\title{
MODULARIZED VALIDATION OF A BUILDING INFORMATION MODEL ACCORDING TO THE SPECIFICATIONS OF THE FACILITY MANAGEMENT HANDOVER AND COBIE
}

\author{
Yongcheol Lee ${ }^{1}$, Eunhwa Yang ${ }^{2}$, Charles M. Eastman ${ }^{3}$ and Kathy O. Roper ${ }^{4}$
}

\begin{abstract}
With increasing requirements and complexity in building projects, diverse domain experts employ a neutral file format, which is exchangeable and interoperable among heterogeneous BIM authoring tools and applications in diverse disciplines. The Construction-Operations Building Information Exchange (COBie) is a set of the specifications of building data exchange pertaining to building asset information. For interoperability, COBie is defined as a model view, which is the subset of the Industry Foundation Classes (IFC) schema. For ensured interoperability of BIM data, using COBie model view, domain professionals and software developers need to identify 1 ) whether their IFC instance files include required information on building asset management and 2) whether their IFC interfaces accurately import/export IFC files according to the COBie specifications. However, since no approach currently supports this validation testing, professionals manually evaluate an IFC instance file and their IFC binding processes in order to identify semantic errors, technical problems, and translation mapping issues. To enhance the efficiency of this timeconsuming and labor-intensive evaluation process, this study proposes a validation framework for evaluating IFC instance files pertaining to the conformity to the COBie specifications. In addition, this study formalizes the requirements of the COBie model view using identified rule logic. For validation, rules are implemented on a modularized validation platform developed on top of the IfcDoc tool, which is a model view documentation and validation tool.
\end{abstract}

Keywords: BIM, IFC, Facility Management, COBie, Interoperability Checking

\section{INTRODUCTION}

The inadequate interoperability among model-based applications costs 15.8 billion dollars by losing its efficiency in the U.S. facilities, of which 10.6 billion dollar loss occurs during operation and maintenance (O\&M) (Gallaher, O'Connor, Dettbarn, \& Gilday, 2004). Data transition among different stakeholders from design to construction and to operation often leads to lack of integration and data loss (Autodesk Inc, 2008). The lack of data integrity and interoperability typically comes from different sources as follows: (1) a lack of

1 Assistant Professor, Department of Construction Management, Louisiana State University, Baton Rouge, LA, U.S., yclee@lsu.edu

2 Assistant Professor, School of Building Construction, Georgia Institute of Technology, Atlanta, GA, U.S., eunhwa.yang@coa.gatech.edu

3 Professor, College of Architecture, Georgia Institute of Technology, Atlanta, GA, U.S., charles.eastman@coa.gatech.edu

4 Associate Professor and Chair, Facility Management, School of Building Construction, Georgia Institute of Technology, Atlanta, GA, U.S., kathy.roper@gatech.edu 
coordination among stakeholders, (2) stakeholders' different internal readiness and adoption of technology, and (3) a lack of standardization (Gallaher et al., 2004).

To ensure interoperability of the data exchange of building information models, diverse disciplines have defined model view definition (MVD) that can reflect their distinct data exchange specifications. MVD consists of concepts that are modularized data sets subject to be reused by several building information modeling (BIM) data exchanges (Hietanen, 2006). In other words, data exchange requirements are specified by aggregating specifications defined in several concept descriptions (Solihin, Eastman, \& Lee, 2015). Thus, one concept can be used several times with different settings of constraints and parameters to fulfill the required specifications of several model views (Lee, Eastman, \& Lee, 2015). One MVD is the Construction-Operations Building Information Exchange (COBie), which is consolidated specifications for exchanging BIM data with regard to building asset information and facility management data (William East, Nisbet, \& Liebich, 2012). As a big stream of current practices in the facility management, it is a key to integrate Computer-Aided Facility Management (CAFM) and BIM technology by using COBie in order to increase the efficiency and effectiveness of commissioning and handover of facility information for O\&M. This can eventually improve day-to-day operation and management of facilities with data accuracy and integrity. However, it is uncertain whether the COBie delivers all information required for facility management (Gnanarednam \& Jayasena, 2013).

\section{PREVIOUS EFFORTS FOR MVD VALIDATION}

Diverse BIM authoring tools such as the Autodesk Revit support exporting facility O\&M data of a BIM model in the Excel sheet according to the COBie specifications. However, in order to share BIM data across various domains, the Industry Foundation Classes (IFC) file should be used and evaluated according to COBie specifications so that end-users (i.e., facility managers, owners) and software developers can easily identify whether received IFC files conform to the COBie requirements and whether IFC exporters of BIM authoring tools accurately translate their native objects to IFC objects.

There have been several efforts to utilize MVD as validation criteria even though the COBie has been not touched. These efforts have been targeted on validating IFC instance files according to particular MVD, not to public MVD such as IFC Coordination View 2.0 or COBie. One study (Lee, Eastman, \& Lee, 2015) surveyed the following two approaches for model view validation: IFC server-based checking and the IfcDoc tool. This paper explains strengths and weaknesses of both semantic validation methods and points out that their rule checking features must be more extended and developed to address diverse checking types. Another available checking method is Global Testing and Documentation Server (GTDS) provided by buildingSMART International (buildingSMART, 2010). GTDS is a server-based application supporting the validation of IFC instance files according to Coordination View 2.0 (CV 2.0). Users, however, cannot look at and modify the specifications of concepts and their corresponding rules. In addition, new model view checker using mvdXML and BIM Collaboration Format (BCF) was proposed for providing a stable IFC validation approach (Zhang, Beetz, \& Weisen, 2015). This paper presents four types of use-cases captured from the Rdg BIM Norm and Statsbygg BIM Manual. The authors of this paper acknowledge that implementable agreements of model views are still insufficient and thus the validation process cannot be strictly applied. The mvdXML specifications and associated rule sets are described in the mvdXML document (Chipman, 
2012). For establishing a robust validation process, the rule types and evaluation scenarios should be accurately identified and executed by a formal checking process (Lee, Eastman, \& Solihin, 2016). As one of effort, the semantic validation process using the precast concrete industry (PCI) MVD was proposed to improve interoperability of BIM data exchange (Lee, Eastman, Solihin, \& See, 2016). The concrete MVD validation process using modularized checking frameworks has assessment features for diverse types of MVD rule sets that can cover PCI MVD specifications. The limitation of this application resides in extending rule definition and execution processes that are only available by hard coding.

To improve the current MVD validation process and enhance this cumbersome procedure regarding facility management and BIM data, this study proposes to develop accurate requirements and associated rule sets of the COBie on top of the IfcDoc tool and to provide a robust MVD validation process. The IfcDoc tool, the model view document generator, has been updated by the ConstructabityTM and the Digital Building Laboratory (DBL) at Georgia Tech so that it can embed diverse validation features that can execute several rule types in terms of model views.

\section{RESEARCH METHOD AND PROCESS}

A number of BIM authoring tools and facility management software have IFC import and export interfaces developed based on the specifications of diverse model views such as $\mathrm{CV}$ 2.0. Since the development of these interfaces can have unexpected errors and omissions, software vendors need to ensure whether their IFC interfaces accurately import/export IFC files according to the COBie specifications. In addition, domain professionals who use such IFC instance files as end-users or owners should confirm whether IFC instance files exported from their software solutions include required information on building asset management. These instance files provide designers or constructors with such customized format for the software of facility managers or owners so that they can demand necessary handover information.

To achieve such goals, this study defines specifications and associated rule-sets of COBie and proposes a validation process of IFC instance files according to the updated COBie requirements. Figure 1 illustrates the data flow of this research using the IfcDoc tool, which is a model view documentation and validation tool.

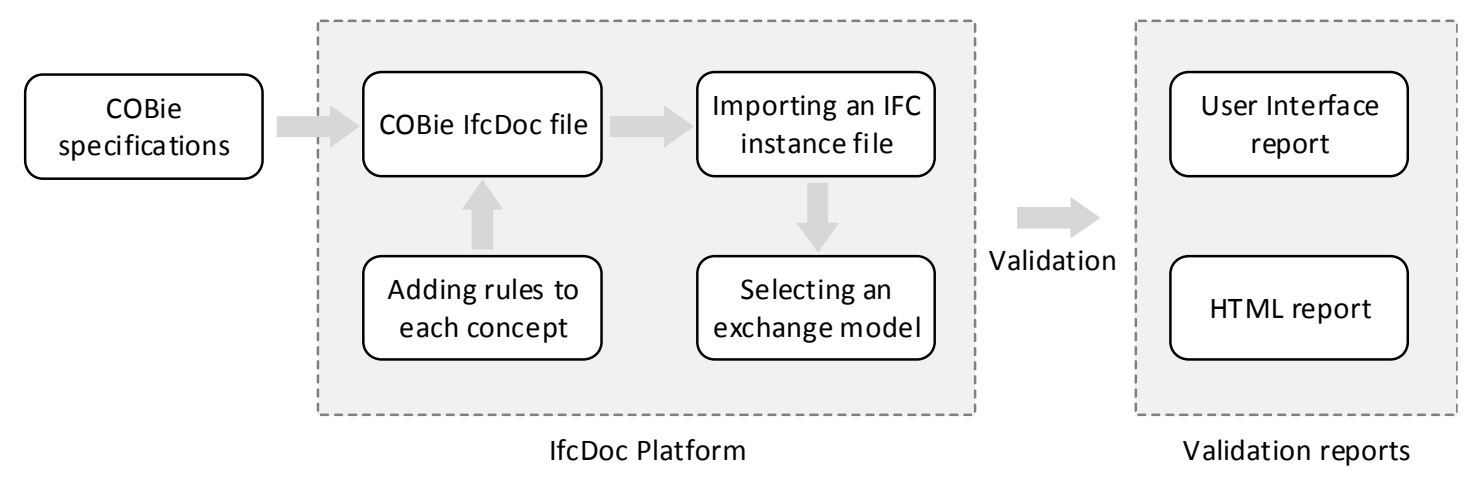

Figure 1: Research processes- Validation of IFC instance files according to COBie

The COBie rule-sets required for evaluating the IFC instance file were developed in concepts of the IfcDoc tool. Each concept entails particular rules associated with an entity, an attribute, a relationship, and a property-set. The rules of concepts are composed as one Exchange Model according to predefined COBie data exchanges. Thus, if a user wants to 
evaluate an IFC instance file according to the Facility Criteria exchange model included in COBie, the concepts of IfcDoc that are contained in the Facility Criteria exchange model are referred and implemented to assess whether the IFC instance file satisfies their rules. The authors utilized the COBie IfcDoc file as a baseline provided from the buildingSMART International website. This COBie IfcDoc file was modified according to new COBie specifications and rule set features of the IfcDoc tool. The updated IfcDoc file was imported to IfcDoc to evaluate an IFC instance file that embeds facility and asset management information. The validation process of this IfcDoc application generates two types of checking reports: a user interface (UI) report and an HTML report. Such reports will be helpful for software vendors to identify errors in inaccurate COBie binding with native objects and to keep track of locations of errors of their IFC exporter of BIM authoring tools. In addition, end-users would be able to ensure their IFC models with regard to conformance to the COBie specifications.

\section{COBie Rule DeFinitions AND TyPeS}

As shown in Figure 2, COBie V2.4 consists of 28 exchange models (EMs) that embed exchange requirements defined for each specific data exchange. Such exchange requirements are formulated by combining several concept descriptions. A concept is a modularized specification for an entity, an attribute, a relationship, and other necessary data (Hietanen, 2006). A concept can be defined by a set of pre-generated concept templates defined based on the structure of the IFC schema. Thus, end-users can manipulate entities, attributes, relationships, and properties of the predefined concept templates in order to facilitate concept definition processes that have duplicated data exchange requirements. Figure 3 represents 16 concept templates that are supposed to define general exchange requirements. Such concept templates are assigned to corresponding entities so that they can use predefined requirements multiple times. Thus, based on the COBie specifications, the authors modified the COBie IfcDoc file and applied rule-sets to each concept template to generate concept definitions required for the COBie model view. The usages of assigned concept definitions for each exchange are defined by the mandatory/optional/none setting underneath each entity on IfcDoc. In other words, if the Metadata concept template in Figure 3 is assigned to the IfcActor entity and is defined as mandatory for the Facility Criteria EM, this EM then includes the specifications that the IfcActor entity must follow requirements correspondingly defined in the Metadata concept template.

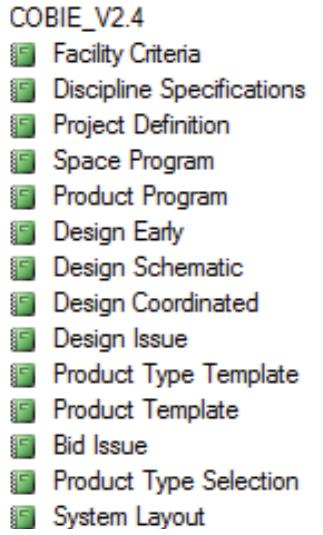

Figure 2: Exchange models of COBie V2.4

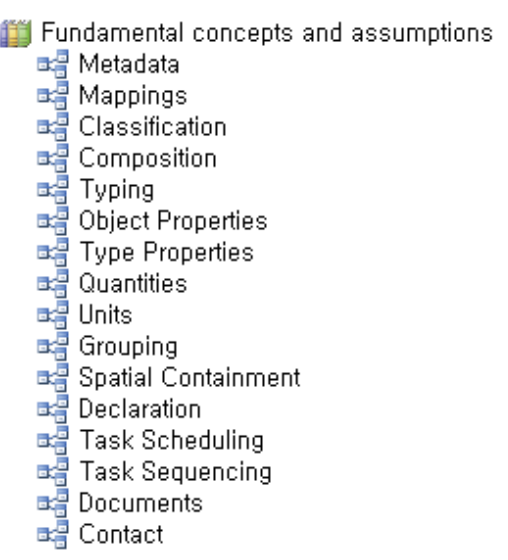

Figure 3: Concepts of COBie V2.4 
The types of the COBie requirements can involve diverse facility O\&M specifications such as space usage, contact information, operations, cost, and maintenance. The following list shows the detailed requirements:

- Authoring information (a person or an application)

- A mapping reference (connection between IFC instances and external data)

- A classification (an OmniClass table)

- A decompose relationship (levels of details)

- An object type (characteristics)

- A property (a property type and value)

- A quantity set (count, length, area, volume, weight, and time)

- A unit (a measurement and data exchange unit)

- A group (member assignment)

- A spatial containment (physical elements in a space)

- A context reference (availability within a project)

- A task scheduling and sequencing (a task and associated date and time)

- An external association (a referenced document)

- A contact information (postal and telecom addresses of an actor and an organization)

These specifications are defined in concept templates and reused by several entities according to their distinct purposes. These concept templates must entail rule sets for each definition in order to be used as validation criteria. The authors identified that COBie V2.4 includes four types of rules: (1) Uniqueness, (2) Semantic accuracy, (3) Relational references, and (4) General syntax checking.

As an example of uniqueness checking shown in Figure 4, the Metadata concept defines that the Name of an object must be unique within the project so that it can support efficient data referencing with external data sets such as tabular data from spreadsheets. Figure 4 shows the IfcDoc interface that allows end users to define information for Metadata.

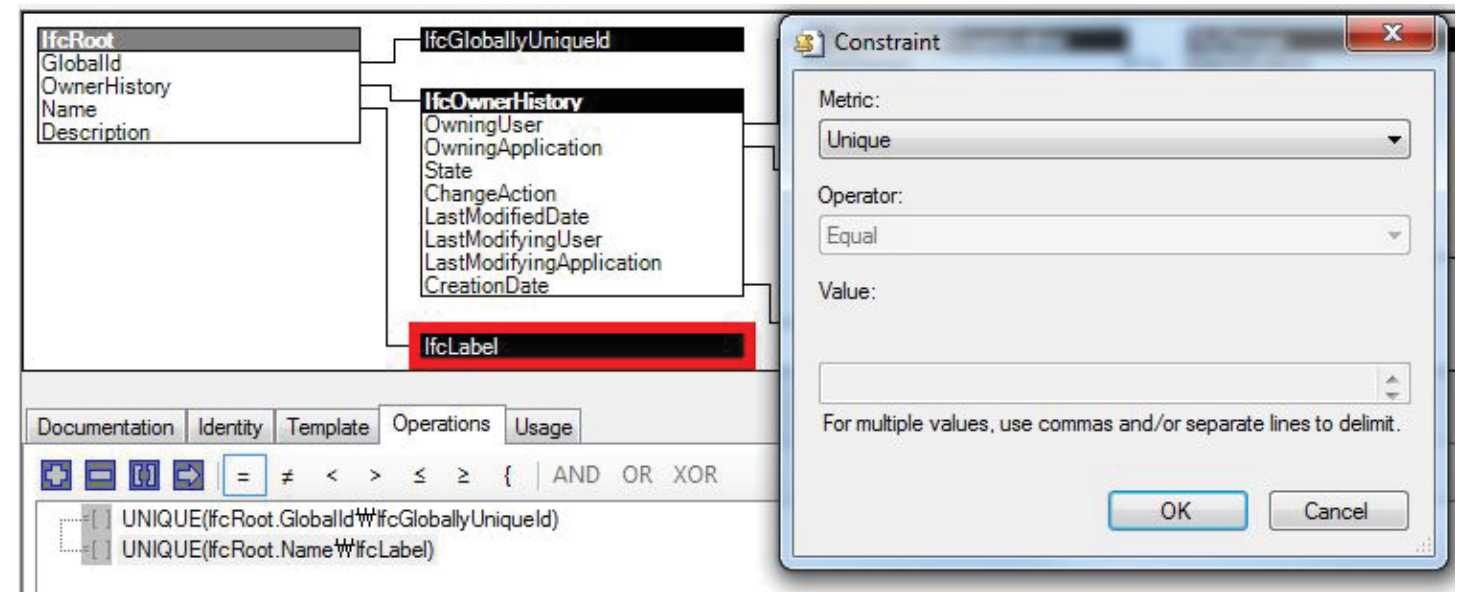

Figure 4: Uniqueness checking of an object name

The second rule type is the accuracy of attribute semantics. The FM Handover model view defines specifications for classification of assets, referring to CSI's OmniClass taxonomy. The Classification concept template defines three parameters that allow each entity to require particular semantics for each attribute. As shown in Figure 5, an IfcBuilding instance should satisfy values defined in Source, Name, and Tokens attributes. 
If IfcBuilding does not meet any one of these values, the validation report shows FAIL for this entity validation.

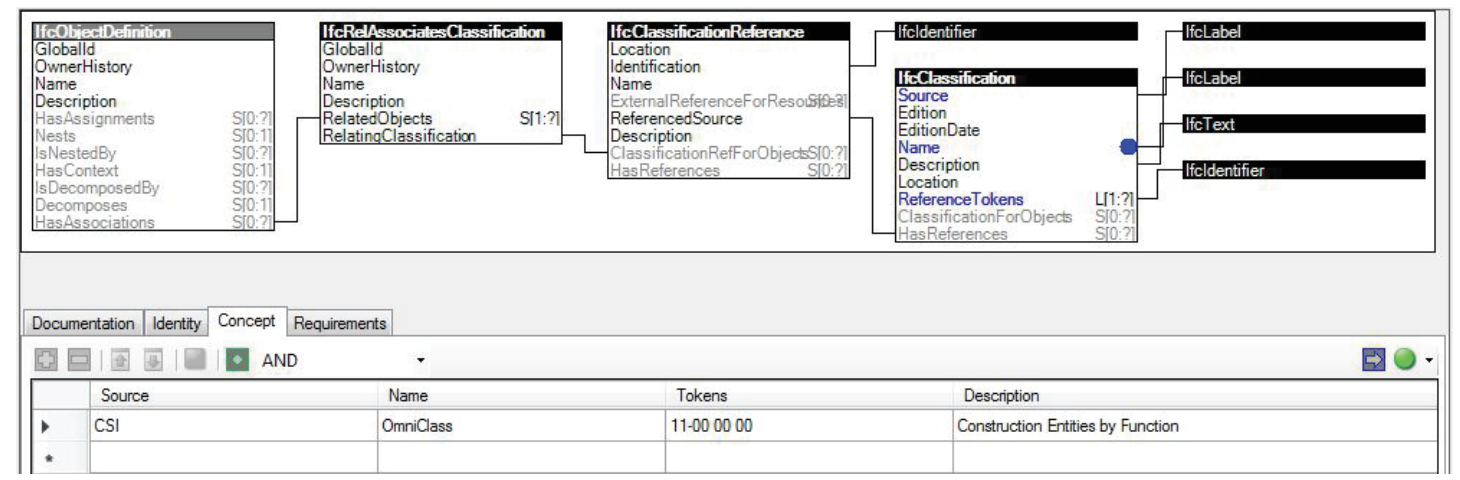

Figure 5: Semantic accuracy checking

Figure 6 shows the rule type of a referential relationship. The composition template defines the relationship between BIM objects: IfcSpace uses this template so as to define the relationship with IfcBuildingStorey. In other words, IfcSpace must have a reference to IfcBuildingStorey to declare the hierarchical composition. In addition, this object relationship defines a spatial containment so that users can identify the spatial clusters or zones of a facility and determine the locations of systems or equipment.

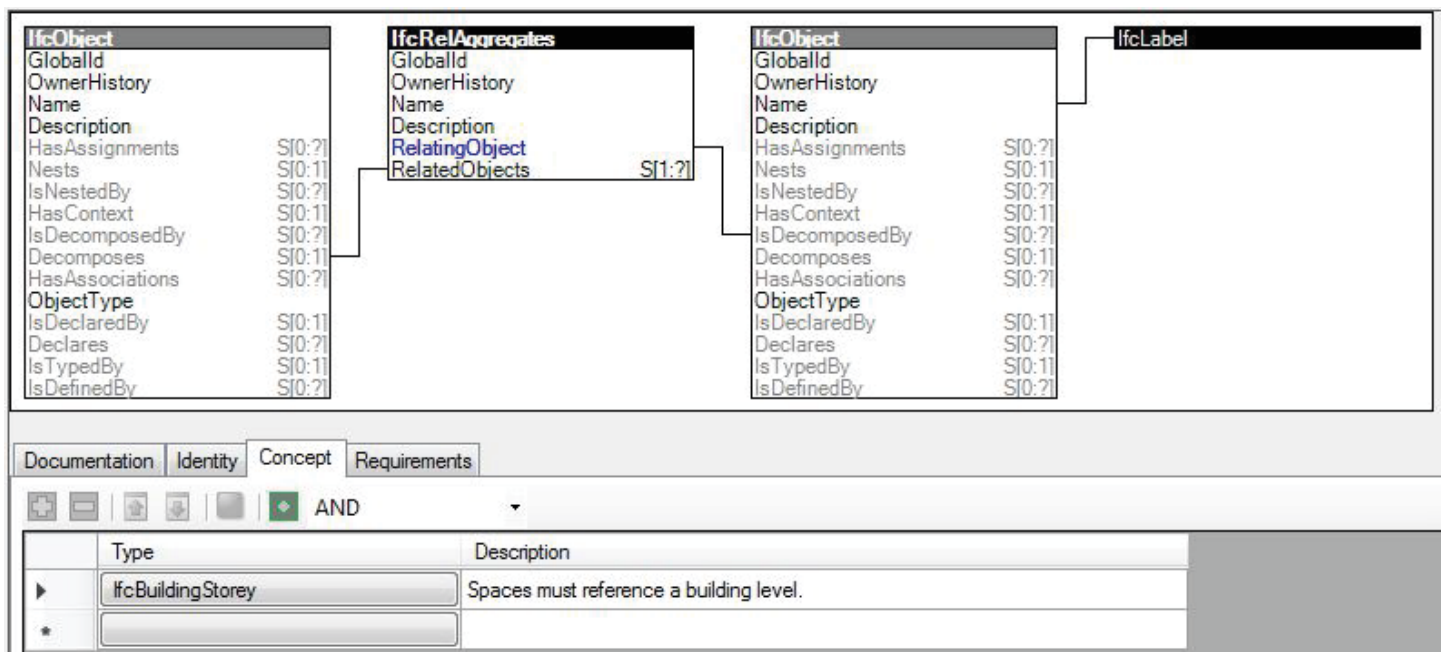

Figure 6: Referential relationship checking

Syntax checking is automatically embedded in a concept template when users define relational reference. For example as shown in Figure 7, an IfcPostalAddress instance must have one IfcLabel for the AddressLines attribute because IfcPostalAddress has AddressLines, which have an arity One-To-Many relationship. 


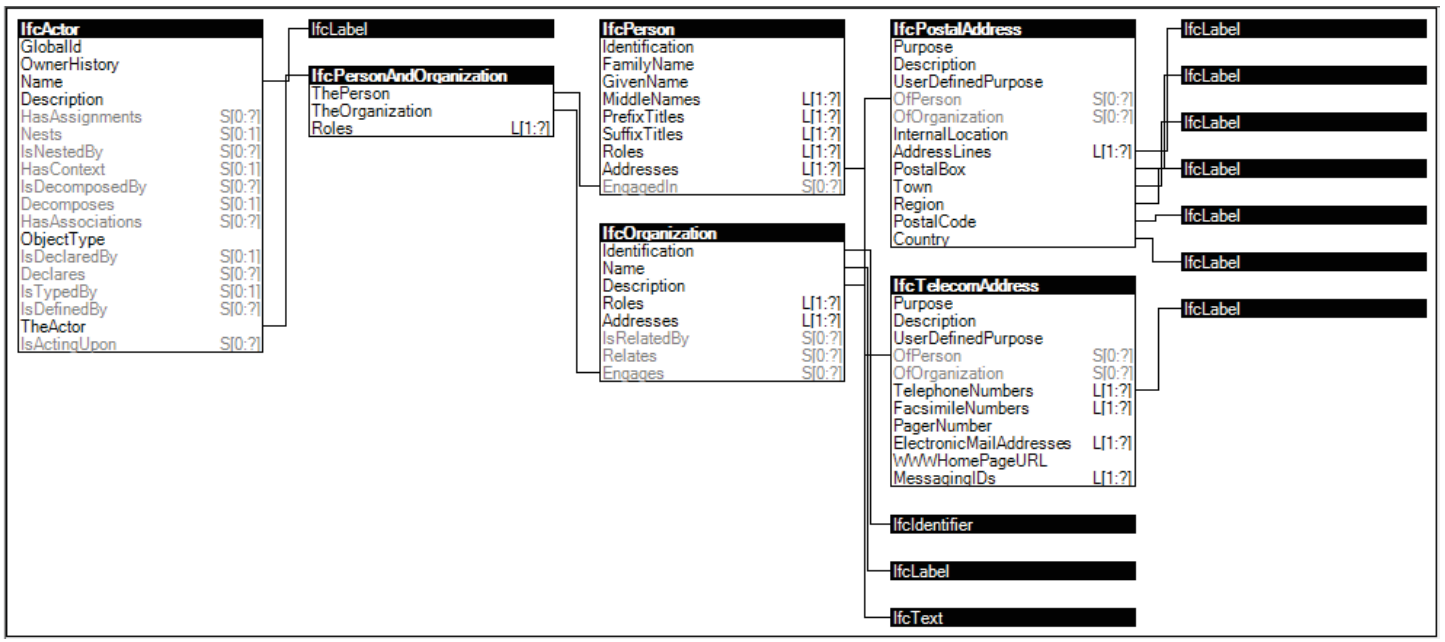

Figure 7: Cardinality checking

\section{VALIDATION OF INSTANCE FILES}

To execute the validation process according to the updated COBie model view, the authors created a sample IFC model for a clinic building shown in Figure 8. This sample model includes spaces and spatial requirements for a doctor, a nurse, a patient, operating, special clinic, X-ray, an exam, a customer service, an information desk, an HVAC, a restroom, and a storage. This model also has several equipment and devices such as nurse calls. In addition, actors and given tasks, element quantities, properties, and schedules were embedded in this model. These facility O\&M data should be thoroughly managed throughout the design and construction phases for availability and passed over to the facility management phase.

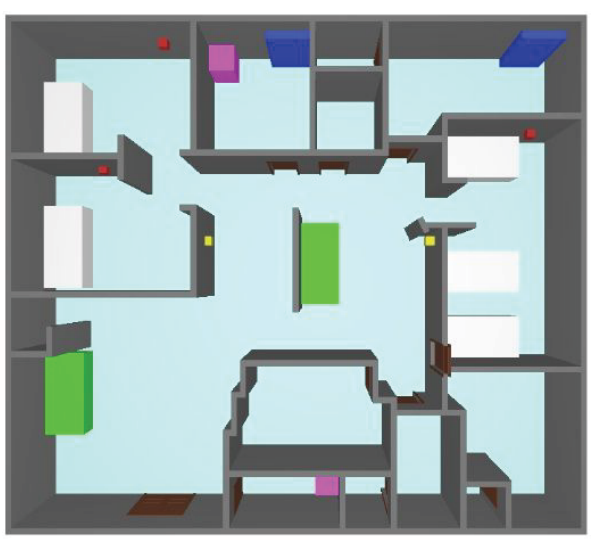

Figure 8: Clinic sample model

To evaluate the developed validation process pertaining to interoperability and model integrity of facility O\&M data of BIM models, the authors implemented the several exchange requirements defined in the COBie model view on the IfcDoc application. Figure 9 shows the validation report of the clinic sample model represented in a user interface report and Figure 10 shows the validation report represented in the HTML format. These validation reports illustrate automatically identified errors in validation of the following red-colored concept templates: Metadata, Mappings, Typing, and Spatial Containment. Opposingly, the passed concepts as follows are represented in green: Composition, Quantities, and Units. In addition, users can identify the causes and the locations of identified errors when they click on a particular instance shown in the right-hand side of the user interface. For example, in Figure 9, the \#66 IfcBuilding instance has an error in validation according to the Metadata concept because it lacks an IfcLabel value for the Name attribute. 


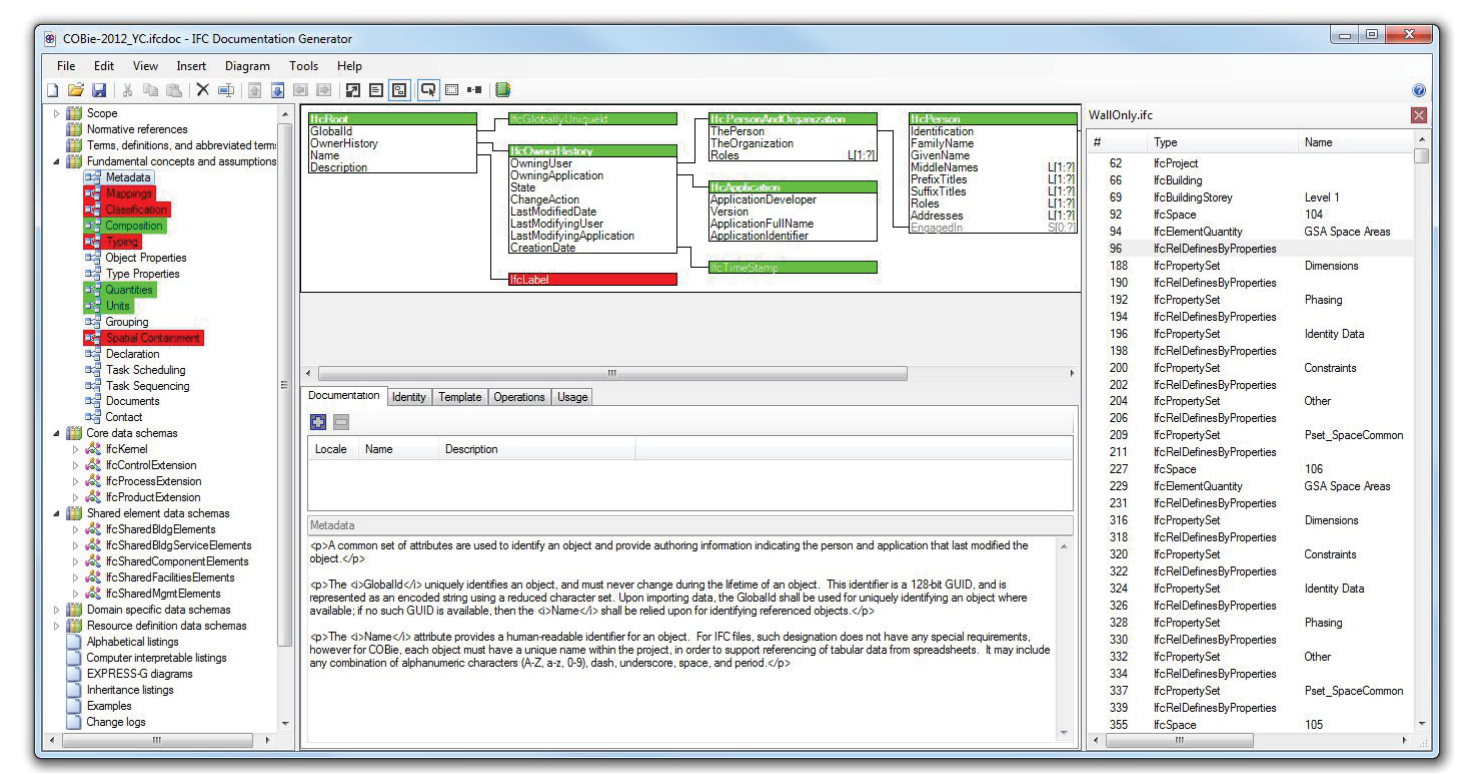

Figure 9: Validation report in the user interface

\section{Validation Results}

\begin{tabular}{|l|l||}
\hline Instance File & C:IYongCheol ClinicSample.ifc \\
\hline Project File & C: $:$ YongCheol COBie-2012_YC.ifcdoc \\
\hline Model View & COBIE_V2.4 \\
\hline Exchange & Space Program \\
\hline Tests Executed & 14 \\
\hline Tests Passed & 3 \\
\hline Tests Ignored & 2 \\
\hline Tests Percentage & $35 \%$ \\
\hline
\end{tabular}

IfcSpace (17)

- Metadata - [FAIL]

- Classification [OPTIONAL] - [FAIL]

Composition

$\checkmark$ Quantities [OPTIONAL]

\begin{tabular}{|l|l|l|l|}
\hline Instance & Type & Name & Structure \\
\hline
\end{tabular}

\begin{tabular}{|l|l|l|l|l|}
\hline \#92 & IfcQuantityArea & GrossArea \\
\hline
\end{tabular}

\begin{tabular}{l|l|l|l|}
$\# 227$ & IfcQuantityArea \\
\hline GrossArea & +
\end{tabular}

\begin{tabular}{l||l|l|l|}
$\# 355$ & IfcQuantityArea & GrossArea \\
\hline
\end{tabular}

\#488 IfcQuantityArea GrossArea +

IfcBuildingStorey (1)

- Metadata - [FAIL]

- Mappings - [FAIL]

$\checkmark$ Composition

\begin{tabular}{|l|l|l|}
\hline Instance & Type & Structure \\
\hline
\end{tabular}

\begin{tabular}{|l||l||l|l|}
\hline$\# 69$ & IfcBuilding & + \\
\hline \hline
\end{tabular}
IfcBuildingElementProxy (16)

\begin{tabular}{|c|c|c|c|c|}
\hline Instance & Space Name? & Element Name? & Structure & Constraints \\
\hline \multirow[t]{6}{*}{$\# 112421$} & Patient room & Fire Alarm & + & + \\
\hline & Patient room & Patient Bed & + & + \\
\hline & Patient room & Nurse Call & $*$ & \\
\hline & Patient room & Faucet & + & + \\
\hline & Patient room & Book Shelf & $*$ & \\
\hline & Patient room & Room Chair & + & + \\
\hline \multirow[t]{6}{*}{$\# 1112421$} & Patient room & Fire Alarm & + & + \\
\hline & Patient room & Patient Bed & + & + \\
\hline & Patient room & Nurse Call & * & \\
\hline & Patient room & Faucet & + & + \\
\hline & Patient room & Book Shelf & * & \\
\hline & Patient room & Room Chair & * & \\
\hline \multirow[t]{6}{*}{$\# 2112421$} & Patient room & Fire Alarm & * & \\
\hline & Patient room & Patient Bed & * & \\
\hline & Patient room & Nurse Call & + & + \\
\hline & Patient room & Faucet & $*$ & \\
\hline & Patient room & Book Shelf & * & \\
\hline & Patient room & Room Chair & * & \\
\hline
\end{tabular}

Figure 10: Validation in the HTML format

In terms of the Quantities concept, each instance conforms to requirements for IfcQuantity. This concept allows element quantity to be represented by IfcQuantityLength named NetHeight and IfcQuantifyArea named GrossArea or NetArea. Since IfcSpace in an IFC instance file uses IfcQuantityArea and its name as GrossArea, this validation shows PASS. Similarly, the Unit concept restricts the possible unit types and measurement values. Such rule checking can be used to require a particularly customized format or unit system that facility managers or owners should use or FM-BIM tools can understand. In addition, the Spatial Containment concept enables validation of the relationships between objects and spaces. For example, given user-defined requirements, IfcSpace named Patient room can be validated as to whether it has a patient bed, a nurse call, a closet, medical equipment, 
or furnishing elements required for the corresponding type of space. Figure 10 shows the spatial containment validation, which shows which IfcSpace satisfies elements defined in the concept. In terms of the Mappings concept, to support automated mapping with a particular file or database, this validation evaluates whether an IFC instance file has persistent connections between IFC data and external ones such as tabular data format used to translate data.

\section{RESUlTS AND DisCUSSIONS}

Complete specification data aggregated during the design and construction phases is invaluable for facility managers who manage the complete building over the decades (Roper \& Payant, 2009). To pass this impeccable data over to facility managers, BIM models must be accurately exchanged among project participants and automatically validated pertaining to implementable specifications defined for each exchange process. With increasing and complex requirements in building projects, binding processes between the COBie and native BIM objects can result in semantic errors, technical problems, and translation issues (William East et al., 2012). In addition, it takes tremendous time to debug errors incurred in the IFC exporting system. For end-users, currently there is no robust approach to evaluating IFC models in terms of the facility management handover and the COBie specifications.

This study proposed a new validation framework, process, and rule sets for validation of IFC models according to the COBie specifications. The formalized COBie requirements and rule sets defined in the IfcDoc tool can be easily executed by the public and software companies. In particular, such requirements and rule sets are able to be reused by other domains and electronically shared with pertinent domain experts. This improved data exchange procedure will reduce tremendous time and effort in managing and monitoring facilities after occupancy. Without these validation processes, the facility manager or operator is left with potentially inaccurate data and the benefits of BIM data become unreliable. The major advantage to having accurate, the reliable data at handover yields advantages in time, efficiency, and productivity during the long operational phase of a facility. COBie is only a format rather than a bi-directional data resource. The validation process for data turn-over should be embedded, resulting in automated, seamless transition of data from design though construction and into operations. Thus, this proposed validation process can resolve almost all of the exchange issues, delivering a clean and reliable set of data for operations. The limitations reside in that current validation only supports checking whether values and contents of an IFC instance file are the same or fulfil the defined rules of COBie. The more intelligent validation and diverse checking features such as a context analysis or a geometry-related rule would be required.

\section{REFERENCES}

Autodesk Inc. (2008). BIM and facilities management, Retrieved September 14, 2015, from http://www.arc-corporate.com/_pdf/bim_and_fm_whitepaperv3.pdf

buildingSMART. (2010). IFC CERTIFICATION 2.0: Specification of Certification Process Chipman, T. L., Thomas; Weise, Matthias (2012). mvdXML V.1-draft: Specification of a standardized format to define and exchange Model View Definitions with Exchange Requirements and Validation Rules. 
Gallaher, M. P., O'Connor, A. C., Dettbarn, J. L., \& Gilday, L. T. (2004). Cost analysis of inadequate interoperability in the US capital facilities industry. National Institute of Standards and Technology (NIST).

Gnanarednam, M., \& Jayasena, H. S. (2013). Ability of BIM to Satisfy CAFM Information Requirements. Paper presented at the The Second World Construction Symposium.

Hietanen, J. (2006). IFC model view definition format. In International Alliance for Interoperability (Ed.): buildingSMART.

Lee, Y.-C., Eastman, C. M., \& Lee, J.-K. (2015). Validations for ensuring the interoperability of data exchange of a building information model. Automation in Construction, 58, pp. 176-195.

Lee, Y.-C., Eastman, C. M., Solihin, W., \& See, R. (2016). Modularized Rule-Based Validation of a BIM Model Pertaining to Model Views. Automation in Construction, 63. pp. 1-11.

Lee, Y.-C., Eastman, C. M., Solihin, W., \& See, R. (2016). An Ontology-Based Approach for Developing Data Exchange Requirements and Model Views of Building Information Modeling, Advanced Engineering Informatics, 30(3), pp. 354-367.

Roper, K. O., \& Payant, R. P. (2009). The facility management handbook: AMACOM Div American Mgmt Assn.

Solihin, W., Eastman, C., \& Lee, Y.-C. (2015). Toward robust and quantifiable automated IFC quality validation. Advanced Engineering Informatics, 29(3), pp. 739-756.

William East, E., Nisbet, N., \& Liebich, T. (2012). Facility management handover model view. Journal of computing in civil engineering, 27(1), pp. 61-67.

Zhang, C., Beetz, J., \& Weisen, M. (2015). Interoperable validation for IFC building models using open standards. ITcon, 20, 24-39. 